\title{
Qualidade na/da educação como um marco referencial das políticas e práticas educacionais: um enfoque multidimensional
}

Marcelo Mocarzel

Jorge Najjar (in memoriam)

\section{Resumo}

Com a utilização do paradigma multidimensional, proposto por Benno Sander, no debate sobre qualidade na/da educação, e a partir de uma retomada históricofilosófica do tema, buscou-se elencar a polissemia do conceito e seus diversos usos e apropriações na literatura educacional. Para além disso, no uso do paradigma, identificam-se as dimensões que constituem qualidade, de modo multidimensional, entendendo-a como um atributo plural e multifacetado. As quatro dimensões são: eficácia pedagógica, eficiência econômica, efetividade política, relevância cultural. Explora-se, assim, uma nova epistemologia da qualidade, que seja negociada em distintos contextos e com os diferentes atores das políticas e práticas educacionais.

Palavras-chave: qualidade da educação; paradigma multidimensional; filosofia e educação. 


\section{Abstract \\ Quality in/of education as a reference framework for educational policies and practices: a multi-dimensional approach}

Through Benno Sander's Multidimensional Paradigm to debate quality in/of education, and by historically and philosophically recovering the theme, it is listed the polysemy of the concept and its various uses and appropriations in educational literature. Furthermore, through the use of the Paradigm, it identifies the dimensions that constitute 'quality', in a multidimensional way, understanding quality as a plural and multifaceted attribute. The four dimensions are: pedagogical efficacy, economical efficiency, political effectiveness, cultural relevance. Thus, a new epistemology of quality is sought after, one which is negotiated in different contexts and with the different actors of educational policies and practices.

Keywords: education quality; multidimensional paradigm; philosophy and education.

\section{Resumen \\ Calidad en/de la educación como un marco de referencia de las políticas y prácticas educativas: un enfoque multidimensional}

Con el uso del paradigma multidimensional, propuesto por Benno Sander, en el debate sobre calidad en/de la educación y desde una reanudación históricofilosófica del tema, se buscó enumerar la polisemia del concepto y sus diversos usos y apropiaciones en la literatura educativa. Además, en el uso del paradigma, se identifican las dimensiones que constituyen calidad, de manera multidimensional, entendiéndola como un atributo plural y multifacético. Las cuatro dimensiones son: eficacia pedagógica, eficiencia económica, efectividad política, relevancia cultural. Así, se busca una nueva epistemología de la calidad, que se negocie en diferentes contextos y con los diferentes actores de las políticas y prácticas educativas.

Palabras clave: calidad de la educación; paradigma multidimensional; filosofía y educación. 


\section{Introdução}

Como qualquer conceito poderoso, há uma série de disputas sobre o que significaria qualidade na/da educação. O fato de utilizarmos as preposições "em" e "de" já demonstra essa disputa: seria qualidade algo construído de fora para dentro ou de dentro para fora? É possível pensar a qualidade de algo sem estar imbricado no processo? Em meio a divergências semânticas traduzidas por distintas concepções epistemológicas e ideológicas, foi-se forjando uma vasta literatura sobre o tema, ao longo de quase um século. Mais recentemente, qualidade tem sido o eixo central de políticas públicas educacionais, na medida em que se tornou princípio e finalidade das ações políticas. É consenso que todos desejam uma educação de qualidade, mas há um complexo debate em torno do que seria essa qualidade na/da educação.

Este texto não tem a pretensão de estabelecer parâmetros e pautar definições sobre qualidade educacional. Pelo contrário, o objetivo central é problematizar o debate, apresentando de forma crítica as nuances e incertezas em torno do conceito e de que forma diversos fatores - como avaliação, gestão, currículo, formação docente, entre outros -, intervêm nas concepções de qualidade. Partimos do pressuposto de que a constituição conceitual do termo é multidimensional (Sander, 2007) e que, portanto, deve ser analisada sob diferentes enfoques para ser compreendida.

A polissemia do conceito, já sinalizada em diversos documentos e por distintos pesquisadores do campo educacional, apenas reforça a complexidade desse objeto de pesquisa. Como fio teórico-metodológico, optamos por reconstituir o caminho que o conceito de qualidade percorreu até ser absorvido pelo campo da educação.

Apesar de não se tratar de um artigo histórico sobre o tema, convém levantarmos alguns marcos internacionais e nacionais sobre o debate da qualidade na/da educação, na medida em que as primeiras formas de emprego do termo permanecem em uso, ainda que confrontadas por variadas abordagens. Trata-se, portanto, de uma conceituação multifacetada, ao mesmo tempo estruturada e estruturante, pois conserva alguns de seus atributos originais, sem abrir mão de variações ao longo do tempo.

Acreditamos que debater a qualidade na/da educação nunca será algo redundante ou esgotável, uma vez que se trata do próprio debate da função social da educação. Discutir qualidade é, em última instância, discutir a educação em sua plenitude, cunhada com base na diversidade, com distintas visões de mundo, buscando que ela cumpra os objetivos traçados e possibilitando que eles sejam superados, transformados e reinventados.

\section{Qualidade como atributo: contribuições da filosofia ao debate}

A primeira importante aplicação do termo qualidade ocorre na obra de Aristóteles e "diz respeito não apenas à característica dos seres e objetos, mas a diferentes maneiras de adjetivá-los, isto é, diferentes tipos de qualidade", segundo 
Santana (2007, p. 27). Ou seja, para o filósofo grego, qualidades eram as propriedades dos seres, hoje chamadas de atributos ou adjetivos.

Essa categoria aristotélica veio sendo debatida ao longo dos anos pela filosofia ocidental. Santana (2007) cita as contribuições de Emmanuel Kant, John Locke e René Descartes, que fizeram suas próprias conceituações de qualidade, sempre relacionadas com a constituição do ser humano. Porém, uma das mais importantes formas de análise da qualidade como conceito foi o seu pareamento com o conceito de quantidade. Assim, como duas dimensões com objetivos radicalmente opostos, passou-se a compreender a qualidade como uma propriedade ontológica.

De acordo com Cury (2010, p. 16 - grifos do autor),

O termo qualidade advém do latim qualitas, mas cuja procedência mais funda é a de poiótês do grego e que significa um título definidor de uma categorização ou classificação. De certo modo, estamos no campo de um atributo distintivo de um bem que passa a se apresentar com uma característica particular além da comum. Por vezes, essa distinção costuma ser assinalada com uma adjetivação como no caso de qualidade social, qualidade total, entre outras.

Ao abordar a dimensão filosófica do debate em torno de qualidade, Cury (2010) faz um levantamento do pensamento aristotélico, já citado, passando por Kant, que entende qualidade como juízos da realidade, e por pensadores de influência marxista, como Friedrich Engels, que, influenciados pela dialética hegeliana, entenderam qualidade como outros modos de ser no mundo, em um movimento de aprimoramento e superação do estágio anterior.

A própria configuração do binômio qualidade-quantidade traz relações vinculadas à superação de estágios anteriores. Durante muito tempo, qualidade e quantidade eram tidas como instâncias opostas; mais do que isso, categorias isoladas de análise. Gatti (2010, p. 29) afirma que "é preciso considerar que os conceitos de quantidade e qualidade não são totalmente dissociados, na medida em que de um lado a quantidade é uma interpretação, uma tradução, um significado que é atribuído à grandeza com que um fenômeno se manifesta", pois, a quantidade, se não for relacionada a um referencial interpretativo, não tem significação em si.

Segundo Demo (2009, p. 9), é equívoco propor um confronto dicotômico entre qualidade e quantidade, pois são facetas do mesmo todo: enquanto quantidade aponta para a extensão, qualidade remete à dimensão da intensidade, da profundidade. Para o autor, "quantidade, para qualidade, é base e condição", ou seja, é outra dimensão da mesma faceta, e nunca negação. Gadotti (2010) aponta que qualidade é a categoria central do novo paradigma de educação e concorda com Demo, mostrando que ela não está separada da quantidade.

A simples oposição entre quantidade e qualidade parece ignorar a complexidade que esse debate envolve. Uma é dimensão da outra. E quando se trata de qualidade na/da educação, é preciso ter em mente os fatores quantitativos que repercutem nos resultados. Por exemplo, qual a qualidade de uma escola para poucos? De que serve uma política executada com excelência que não ocupa seu caráter público e democrático? Compreender o funcionamento orgânico do binômio 
qualidade-quantidade é algo que pode contribuir para análises mais complexas do contexto educacional.

\title{
Qualidade na/da educação: primeiros usos e recentes aproximações
}

O levantamento histórico do emprego da ideia de qualidade na/da educação é tarefa complexa, na medida em que há dois complicadores: a) muitos termos análogos vêm sendo utilizados para representar qualidade, ainda que sem a mesma força de definição; b) a forma dissipada com a qual a terminologia foi utilizada ao longo do século 20, ganhando força ao ser assumida em textos oficiais de educação de organismos internacionais nas décadas de 1980 e 1990.

\begin{abstract}
Em uma definição mais corriqueira, a qualidade é tomada como propriedade, atributo ou condição das coisas ou pessoas, capaz de distingui-las das outras e de lhes determinar a natureza. Isto implica que o conceito de qualidade sempre pressupõe parâmetros comparativos, que permitam a distinção entre o que se julga uma boa ou má qualidade, particularmente quando se focalizam fenômenos sociais. Sendo assim, na condição de um atributo, a qualidade e seus parâmetros integram sempre o sistema de valores que predominam em cada sociedade, o que significa dizer que sofrem variações de acordo com cada momento histórico e, portanto, de acordo com as circunstâncias temporais e espaciais. (Azevedo, 2011, p. 422).
\end{abstract}

Ainda assim, há algumas pistas que nos levam ao debate, sobretudo quando pensamos que qualidade é um conceito que veio do mundo empresarial para o mundo educacional e não o contrário, por mais que tenha sido debatido em sua dimensão filosófica desde Aristóteles. No século 20, o mundo empresarial se apropria do termo e o utiliza como juízo de valor para outras instâncias, como produtos, processos e mecanismos, como sinônimo de algo "bom".

Atribui-se ao termo qualidade valor "positivo", mas não se explica o que é ser "bom", cada pessoa o interpreta a seu modo. Essa concepção está associada a um modelo desenvolvido no mundo empresarial em meados do século XX, chamado de qualidade total, que influenciou a interpretação da qualidade em geral. A partir de então o termo qualidade adquiriu importância e passou a ser sinônimo de algo "positivo", capaz de proporcionar benefícios para a empresa e/ ou para o cliente-consumidor. Esse modelo não quer discutir o que é qualidade, mas impor uma conotação "positiva" ao termo em favor da competitividade e dos valores da sociedade capitalista. (Santana, 2007, p. 29).

Em educação, uma das primeiras aparições do termo pode ser vista em John Dewey, ainda que não seja da forma como o utilizamos hoje. Em 1916, o filósofo da educação lança a obra Democracia e educação, nos Estados Unidos, na qual estabelece parâmetros para discutir, entre outros assuntos, a experiência como meio educativo. Em 1938, mais de 20 anos depois, ele publica Experiência e educação, livro no qual consolida sua teoria da experiência. Na primeira obra, Dewey (1936, p. 11 - grifo nosso) já começa a estabelecer um debate sobre a qualidade da experiência, quando demonstra a etimologia do termo educação e afirma: "Uma vez que o que se requer para isso é a transformação da qualidade da experiência, para que nesta entrem os interesses, intuitos e ideias correntes no grupo social, o problema não é, 
evidentemente, o da mera formação física". Mesmo de forma tímida, ele começa a apontar para uma visão de qualidade como objetivo da educação, ainda que use o sentido de experiência de forma mais ampla.

A evidência do tratamento sobre qualidade em Dewey pode ser comprovada com mais clareza no Brasil, na medida em que seu principal discípulo brasileiro, Anísio Teixeira, utiliza a concepção de forma recorrente. A começar pelo Manifesto dos Pioneiros da Educação Nova, publicado em 1932 e concebido por intelectuais como o próprio Anísio, Fernando de Azevedo, Sampaio Doria, Paschoal Leme, entre outros. Nesse documento (Azevedo et al., 1932), por duas vezes, a expressão "qualidade socialmente útil" é empregada para evocar a importância de que a finalidade da educação sirva a todos, e não a uma classe. O mesmo argumento é revisitado por Anísio Teixeira (1957) em Educação não é privilégio, ao apontar que a qualidade da escola brasileira é seletiva, por se dirigir a formar e manter uma elite em detrimento do povo em geral. Afirma, por outro lado, que uma educação boa e de qualidade é cara, exige investimento à altura e é uma opção política.

Assim, começa a popularizar-se, no Brasil, o uso do termo qualidade na/da educação como objetivo de políticas e práticas educacionais, mas, como mencionado, o emprego de aparentes sinônimos também favoreceu o acirramento da disputa pelas concepções de qualidade. Nos Estados Unidos, por exemplo, vasta literatura dos anos 1960 e 1970 passou a congregar novas - ou renovadas - terminologias relacionadas à qualidade na/da educação como, por exemplo, "desempenho" (Coleman et al., 1966; Mager; Pipe, [1970] 1976), "aproveitamento educacional" (Jencks, 1972) e "eficácia" (Madaus; Airasian; Kellaghan, 1980).

Poucas publicações tinham como enfoque a ideia de qualidade. Conseguimos resgatar o livro The quality of education in developing countries, escrito em 1966 por Clarence Edward Beeby, que ocupou o cargo de diretor de educação da Nova Zelândia. Especialista em planejamento de sistemas educacionais, Beeby foi influenciado pela sua participação na Conferência em Educação e Desenvolvimento Social e Econômico, realizada em Santiago do Chile, em 1962, pela Organização das Nações Unidas para a Educação, a Ciência e a Cultura (Unesco).

No início de sua argumentação, Beeby (1966) demonstra o dilema existente entre aumentar rapidamente a oferta de educação elementar ou garantir a qualidade da educação existente, restringindo o acesso àqueles com condições de obter sucesso. Segundo ele, como em países em desenvolvimento a grande maioria dos pais dos alunos era analfabeta, a pressão por mais educação (expansão quantitativa) acabou por superar a pressão por melhor educação (melhores resultados), o que se tornou um movimento mundial a partir de então. Ao analisar esse quadro de expansão e defendendo que o alargamento do acesso não necessariamente diminuiria a qualidade, Beeby buscou criar instrumentos para se definir o que, então, seria qualidade educacional.

A qualidade na/da educação, segundo Beeby (1966, p. 10 - tradução nossa), se daria em três diferentes níveis e o mais simples pode ser descrito como "nível de qualidade da sala de aula". Nele estariam algumas habilidades mensuráveis, como a aprendizagem de leitura, escrita e matemática, o fluxo escolar e os resultados em exames, mas também outras mais subjetivas, como iniciativa, criatividade e respeito 
à autoridade (algo próximo à ideia de disciplina). Alguns desses atributos acabam por ir além da sala de aula e atingem o próximo nível descrito por ele.

O segundo seria o "nível da qualidade no mercado", cuja mensuração se daria pelo grau de produtividade. Nesse quesito, a visão econômica seria dominante, e a eficiência seria controlada por meio dos insumos investidos e dos resultados aferidos após o processo educativo. Beeby (1966) critica a visão economicista pura, indicando que esse modelo ainda não havia se provado capaz de determinar a qualidade ou não dos sistemas, gerando visões extremamente divergentes entre economistas e gestores educacionais, por exemplo.

O terceiro e último é o "nível de qualidade dos critérios sociais", ou o que hoje chamaríamos de senso comum. Segundo Beeby (1966, p. 12 - tradução nossa), nesse nível, "todo mundo se tornaria um expert em educação e cada um de nós passaria a julgar o sistema escolar em termos dos objetivos finais que traçamos para nós mesmos, nossas crianças, nossa comunidade, nosso país".

Nesse sentido, Beeby foi precursor do debate sobre a polissemia da qualidade na/da educação, bem como inaugurou uma visão multidimensional sobre o tema, algo que buscaremos fazer a partir do paradigma multidimensional proposto por Sander (2007). Fortemente influenciado pelos debates nas conferências promovidas pela Unesco, o paradigma de Sander surge num contexto em que a educação ganha força como elemento de desenvolvimento dentro de um ideário macroeconômico keynesiano, ${ }^{1}$ bastante popular entre os governos no período posterior à Segunda Guerra Mundial. Ainda que tenhamos textos expondo a problemática da qualidade na/da educação, o uso desse conceito só ganhou corpo quando da sua utilização por organismos internacionais, como a Unesco, o Banco Mundial e a Organização para Cooperação e Desenvolvimento Econômico (OCDE). De acordo com Silva (2008), foi constituída uma narrativa instrumental para o uso do conceito de qualidade, na medida em que a terminologia comporta diferentes enfoques.

Adams (1993, p. 7 - tradução nossa) aponta que pelo menos seis visões diferentes sobre o que seria qualidade na/da educação podem ser encontradas na literatura especializada: "qualidade como reputação; qualidade como recursos e investimentos; qualidade como processo; qualidade como conteúdo; qualidade como resultados; qualidade como valor agregado".

No final dos anos 1980 e início dos anos 1990, a apropriação do termo qualidade passou a ter protagonismo em documentos internacionais, considerando os diferentes enfoques apontados por Adams (1993). Por exemplo, tanto o documento Educação na África Subsaariana (Banco Mundial, [1988] 1990) como a Declaração Mundial sobre Educação para Todos (1990) defendem uma visão de qualidade como os resultados alcançados a partir de determinado cumprimento de metas.

Em 1995, o Banco Mundial reafirma essa visão, ao lançar o documento Prioridades e estratégias para a educação (World Bank, 1995). O texto sistematiza as prioridades alegadas para a educação nos países em desenvolvimento, referenciado por diversos estudos e experiências anteriores, nas mais diferentes realidades. Entre as questões prioritárias apontadas, estão a garantia da equidade, que nesse caso

\footnotetext{
${ }^{1}$ A teoria do inglês John Maynard Keynes (1883-1946) serviu de base para o modelo econômico desenvolvimentista, aliando uma forte e marcante presença do Estado como indutor do desenvolvimento e moderador do mercado, fazendo um contraponto tanto ao modelo liberal como ao modelo socialista.
} 
trata-se de minimizar os diferentes níveis de acesso à educação entre classes, gêneros e grupos étnicos; o controle financeiro por meio da eficiência dos processos; a busca de novas fontes de recursos; e a criação de padrões (standards) e motivadores (inputs); entre outros. Segundo o documento:

A qualidade da educação é pobre em todos os níveis nos países subdesenvolvidos e em desenvolvimento. Estudantes dos países em desenvolvimento têm índices de aprendizagem menores que os dos países industriais e sua performance possuiu uma maior variação. (World Bank, 1995, p. 3 - tradução nossa). ${ }^{2}$

Essa visão de que a educação nos países em desenvolvimento tem menos qualidade do que nos países industrializados faz com que o modelo europeu e norteamericano seja a principal referência para o pacote de medidas implementadas no resto do mundo. Ou seja, o modelo eurocêntrico presente desde a antiguidade, por mais que hoje tenha uma nova distribuição geográfica, ainda persiste.

Esse pacote de medidas do Banco Mundial visa à redução da pobreza como forma de perpetuação do capitalismo no mundo. Isso é claro, uma vez que o controle do organismo está sempre polarizado entre Europa e Estados Unidos, num revezamento histórico que inclui a presidência do Fundo Monetário Internacional (FMI). Tais medidas são baseadas em estudos e pesquisas, contendo um ar de receituário e ignorando certas especificidades geográficas e culturais. Torres (2000, p. 138) indica que as propostas do Banco Mundial para a educação são criadas basicamente por economistas: "A relação custo-benefício e a taxa de retorno constituem as categorias centrais a partir das quais se define a tarefa educativa, as prioridades de investimento (níveis educativos e fatores de produção a considerar), os rendimentos, e a própria qualidade".

Nesse modelo, o tecnicismo vem à tona. A grande crítica de Torres ao modelo imposto pelo Banco Mundial é a ausência da pedagogia e dos pedagogos em suas propostas. Trata-se de um pacote moldado pelo fator econômico, que impõe generalizações, com conhecimentos insuficientes do âmbito educativo, com um viés ocidental e anglo-saxão e guiado pelas leis do mercado, pois "o ensino resume-se a um conjunto de insumos (inputs) que intervêm na caixa preta da sala de aula" (Torres, 2000, p. 140).

Pela lógica do Banco Mundial, há práticas que são "avenidas promissoras" e práticas que são "becos sem saída", ou seja, não dão certo nem nunca darão e devem ser abandonadas. Esse enfoque de manual faz com que certas "avenidas" sejam privilegiadas em função do custo-benefício. São privilegiados insumos como material didático, tempo de instrução e capacitação em serviço, em detrimento de outros tidos como menos eficientes (salário do professor, tamanho das classes e estrutura física das escolas).

As propostas educacionais do Banco Mundial são apresentadas como leis universais, muito celebradas e pouco explicitadas, tratando os conteúdos como

\footnotetext{
2 "The quality of education is poor at all levels in low-and middle-income countries. Students in developing countries have a mean level of achievement below that in industrial countries, and their performance shows a much greater variation around the mean."
} 
currículo sem propostas didáticas efetivas e com dados mascarados, segundo Torres (2000). A qualidade, sob essa ótica, é centrada nos resultados, pois não se permitem flexibilizações e se exige a adoção do pacote completo.

Do mesmo modo, outros organismos se transformaram em indutores técnicos da qualidade educacional, como a OCDE, a Comissão Econômica para América Latina e Caribe (Cepal), o Programa das Nações Unidas para Desenvolvimento (Pnud) e o próprio Fundo das Nações Unidas para a Infância (Unicef), segundo Dourado, Oliveira e Santos (2007). Esses organismos multilaterais possuem suas próprias conceituações de qualidade. A Unesco, por exemplo, aponta quatro dimensões que a compõem - pedagógica, cultural, social e financeira - e articulam a avaliação à qualidade.

No início dos anos 2000, a Organização das Nações Unidas (ONU), por meio do Unicef e da Unesco, publicou dois documentos centrados no debate da qualidade na/da educação. Ambos se tornaram marcos. O primeiro foi Definindo qualidade em educação (Unicef, 2000), no qual são apontados cinco campos da qualidade a serem revisitados: qualidade dos aprendentes; qualidade dos ambientes de aprendizagem; qualidade dos conteúdos; qualidade dos processos; e qualidade dos resultados.

O segundo documento coloca a qualidade nas manchetes, na medida em que traz um título provocador: Educação para todos: o imperativo da qualidade (Unesco, 2005) e trata a qualidade como um imperativo, definindo, de maneira categórica, o que seria qualidade a partir de determinados insumos, buscando superar uma suposta dicotomia. Nas palavras do relatório:

As diversas abordagens à qualidade têm suas raízes em diferentes tradições de pensamento educacional. Abordagens humanistas, teoria behaviorista, críticas sociológicas da educação e desafios ao legado do colonialismo enriqueceram o debate sobre qualidade, e produziram visões distintas dos objetivos educacionais que devem ser alcançados. Para conciliar uma diversidade de abordagens, o Relatório adota uma estrutura que leva em consideração cinco fatores principais que afetam a qualidade: os alunos, cuja diversidade deve ser reconhecida; o contexto nacional econômico e social; os recursos materiais e humanos; o processo de ensino e aprendizagem; e os resultados e benefícios da educação. Ao focalizar essas dimensões e a maneira como interagem, é possível fazer um mapeamento para compreender, monitorar e aprimorar a qualidade. (Unesco, 2005, p. 19).

Esse documento, diferentemente dos do Banco Mundial, que possuem uma clara visão economicista da educação, tenta passar ao largo de debates ideológicos sobre o conceito de qualidade da/na educação. Assim, elencando apenas as cinco dimensões citadas, a Unesco busca desviar-se de críticas políticas, tentando estabelecer uma suposta neutralidade no tratamento do tema, ainda que uma análise mais apurada mostre que isso não ocorre.

No Brasil, a partir de todas essas contribuições, em 2007 o Ministério da Educação, por meio do Instituto Nacional de Estudos e Pesquisas Educacionais Anísio Teixeira (Inep), publicou um texto intitulado A qualidade da educação: conceitos e definições (Dourado; Oliveira; Santos, 2007). O documento é crítico a visões totalizantes expedidas pelos organismos internacionais, afirmando que o simples reconhecimento de insumos não dá conta da complexidade do debate sobre qualidade, mesmo que a existência desses insumos implique a qualidade da escola. 
É extensa a lista de elementos que podem ser considerados indispensáveis para uma educação escolar eficaz, assim como são profundos e diversificados os aspectos que podem levar a uma compreensão consistente da problemática, em razão da multiplicidade de significados do que seja uma boa educação ou uma escola de qualidade. Assim, só tem sentido falar em escola de qualidade ou escola eficaz se considerarmos um conjunto de qualidades ou de aspectos envolvidos. (Dourado; Oliveira; Santos, 2007, p. 10).

Ainda que o artigo 206 da Constituição Federal, de 1988, e o artigo $3^{\circ}$ da Lei de Diretrizes e Bases da Educação Nacional (LDB), de 1996, falem em "garantia de padrão de qualidade", a falta de clareza do que seria esse padrão resulta em dificuldades de fiscalização, monitoramento e responsabilização diante da não efetivação do direito.

Portanto, se por um lado não podemos reduzir qualidade na/da educação a simples insumos que atendidos garantiriam sua efetivação, por outro, não podemos deixar de considerar, na construção de políticas e práticas educacionais, alguns elementos fundantes que são condicionantes da qualidade e por ela são, de modo reflexivo, também condicionados.

\section{O paradigma multidimensional}

Diante da polissemia encontrada no uso e na interpretação do termo qualidade na/da educação, buscamos um arcabouço teórico que possibilitasse uma discussão mais alargada da temática, no intuito de contribuir para o campo. Assim, pensando qualidade como um conceito plural, interpretativo, que pode ser enquadrado a diferentes contextos, encontramos no paradigma multidimensional (Sander, 2007) uma oportunidade de avançar o debate. Essa escolha se justifica pela proximidade dos debates entre gestão e qualidade, possibilitando o emprego dessa teoria na análise, mas também compreendendo que, do ponto de vista metodológico, o paradigma aponta caminhos para a pesquisa e também organiza categorias prévias.

Sander (2007, p. 88) explica que, na década de 1980, na tentativa de construir uma teoria analítica sobre a genealogia do conhecimento do campo da gestão em educação no Brasil, acabou elaborando um "paradigma heurístico", de "caráter multirreferencial", buscando dar conta das desconstruções e reconstruções históricas que o conceito de administração/gestão educacional sofreu.

Tomamos emprestado o paradigma multidimensional, conscientes de que o conceito foi concebido para estudar um campo específico, mas confiantes de que sua base teórico-epistemológica promove justamente um olhar panorâmico sobre as influências históricas que vão (de)formando um conceito. Além disso, os pressupostos da qualidade na/da educação estão amplamente relacionados aos da gestão educacional, pois compreendemos que o fim da questão é promover, em alguma medida, a qualidade.

A multidimensionalidade do campo educacional apontada por Sander (2007) corrobora justamente com a possibilidade de utilização dessa estrutura em um contexto diferente, ainda que guardadas as devidas particularidades. Segundo o 
autor, a visão pós-estruturalista no campo da educação e das ciências sociais trouxe ao meio acadêmico possibilidades antes impensáveis de se articular diferentes paradigmas conceituais e analíticos. Porém, para Sander (2007), o paradigma multidimensional vai além de um simples enfoque multiparadigmático, pois, ao invés de tentar articular eixos divergentes, busca construir um referencial baseado na teoria da complexidade de Edgar Morin. A ideia é a de que o pensamento complexo, em oposição ao pensamento simplificado, não busca a totalidade das coisas. Segundo Morin (2007, p. 72), "nas coisas mais importantes, os conceitos não se definem pelas suas fronteiras, mas a partir de seu núcleo". Nessa concepção epistemológica, as ideias estão interligadas e se relacionam com o contexto, se transformam a partir de diferenciados enfoques.

Dessa forma, as análises baseadas na "simultaneidade" superam aquelas ancoradas na "sucessividade de tempos e etapas" (Sander, 2007, p. 92), pensamento vigente por muito tempo no campo da educação. Temos, portanto, a visão de que a diversidade de pensamentos e as concepções se mantêm mesmo fora de um eixo histórico pré-determinado e que a complexidade das diferentes abordagens é a chave de entendimento conceitual. O paradigma multidimensional, no caso da administração/gestão em educação, é constituído

[...] por quatro dimensões simultânea e dialeticamente articuladas: dimensão econômica, dimensão pedagógica, dimensão política e dimensão cultural. A cada dimensão analítica corresponde um critério de desempenho administrativo hegemônico, respectivamente: eficiência, eficácia, efetividade e relevância". (Sander, 2007, p. 92 - grifos do autor).

Ao compreendermos qualidade na/da educação a partir de uma visão complexa, em que os diferentes elementos que a constituem são inseparáveis, constitutivos do todo e relacionados aos contextos (Morin, 2007), podemos fazer a análise desse conceito à luz do paradigma multidimensional, utilizando as quatro dimensões e os respectivos critérios apontados.

\section{O paradigma multidimensional da qualidade na/da educação}

A própria ideia de paradigma traz em si a dialética como elemento constituinte. Um paradigma pode ser entendido como um modelo, um padrão, de acordo com o Dicionário Aurélio (Ferreira, 1999). Pode ser entendido também, a partir da visão de Kuhn (1982), como um patamar de conhecimento totalizante de uma determinada época. A concepção de Sander (2007), aplicada à administração/gestão, traz grandes contribuições, por si só, à temática da qualidade.

Entretanto, na aplicabilidade do paradigma especificamente à questão da qualidade na/da educação, algumas adaptações se fazem necessárias para recortarmos a temática com mais propriedade e enxergarmos nela o uso das dimensões apontadas. Assim, afirmamos que qualidade é uma construção plural, que envolve aspectos diversos e se constitui a partir de seus próprios objetivos, não importa se estamos falando de qualidade social, socialmente referenciada, total ou economicista. Cada 
uma dessas denominações traz, nesse modelo teórico, o predomínio de uma ou mais dimensões sobre as demais.

Assim, assume-se que a qualidade pode ser maior a partir do privilégio de uma área em detrimento de outra: ao buscar uma qualidade social devem ser evidenciadas as dimensões sociais em detrimento das econômicas, ou vice-versa. No modelo que construímos, a riqueza da qualidade na/da educação se dá justamente pela garantia de todas as dimensões, por mais que, de maneira analítica, possamos realizar interpretações de diferentes tipos de qualidade, como eles de fato se dão no mundo.

\section{Dimensão da eficácia pedagógica}

Diferentemente das dimensões ligadas à administração, apresentadas por Sander (2007), optamos por iniciar com a dimensão pedagógica, de modo a marcar sua centralidade no debate sobre qualidade na/da educação. Ainda que todas elas sejam intrínsecas ao debate e que congreguem elementos importantes para a definição de qualidade, ao falarmos de educação, a dimensão pedagógica ganha certo relevo, por se tratar do objeto em si. Sander (2007, p. 97) já havia percebido isso ao construir as bases do modelo analítico para a administração: "Através dos anos, a dimensão pedagógica da administração da educação tem sofrido um processo de atrofia diante da ênfase generalizada em considerar o sistema educacional em função do desenvolvimento econômico e tecnológico".

No que tange ao debate sobre qualidade na/da educação, entendemos que há também esse movimento: muitas vezes os critérios interpretativos de qualidade privilegiam os aspectos da eficiência econômica em detrimento dos educacionais. Um exemplo clássico é a comparação entre universidades públicas e privadas, quando se acusa instituições públicas de gastarem demais, de serem "inchadas", na esteira das políticas baseadas na ideia quase-mercado, que exaltam a ineficácia do Estado (Souza; Oliveira, 2003) e a privatização como única possível saída.

Nessa dimensão, o critério da eficácia também pode ter dupla serventia. Se por um lado podemos enxergar a eficácia como um elemento importante de avaliação das políticas e práticas, por outro, pode ser uma medida que ignora aspectos cruciais da realidade. Assim, a dimensão pedagógica precisa garantir direitos básicos aos alunos: acesso à escola e permanência nela; profissionais da educação com boa formação inicial e continuada; currículos e materiais didáticos que dialoguem com a diversidade; planejamento e avaliação adequados aos objetivos pedagógicos; e garantia da aprendizagem e da formação integral dos sujeitos.

A eficácia pedagógica pode ser enquadrada em diferentes concepções. Uma delas, com ampla literatura de suporte, constitui-se naquilo que Sammons (2008, p. 343) entende como uma superação das expectativas em relação aos alunos ou "um valor adicional aos resultados". A eficácia seria, nesse viés, o progresso além do esperado em relação aos estudantes de um determinado contexto. Assim, eficácia em educação seria um conceito relacionado às condições que previamente se apresentam. 
A noção de eficácia pode se aproximar da noção de qualidade, porque a qualidade pode ser vista como um ideal a ser alcançado. Por outro lado, pode significar o seu completo oposto, se tomada como um pré-requisito para a competição e para tornar invisíveis as diferenças, naturalizando a desigualdade de oportunidades educacionais.

A crença é a de que as pressões geradas pela competição, suscitada pelos procedimentos avaliativos, farão com que sejam mobilizados processos e recursos que resultarão em melhoria da qualidade de ensino. Desse modo, pressupõe-se a aceitação da desigualdade como condição mesma de produção de qualidade, pois sendo diferentes e diversificadas as condições dos sistemas e unidades escolares estaríamos caminhando na direção de intensificar os processos de segregação e seleção educacional e social. (Souza; Oliveira, 2003, p. 890).

Entender a dimensão da eficácia pedagógica da qualidade a partir de uma visão estritamente ancorada em resultados traz problemas interpretativos, uma vez que desconsidera o contexto do/no qual se fala, tão importante para se compreender as diferenças de oportunidades e trajetórias. O pensamento complexo (Morin, 2007) exige que as teias de relações sejam incorporadas nas análises, pois sem elas simplificamos e empobrecemos as ideias.

\section{Dimensão da eficiência econômica}

A segunda dimensão da qualidade na/da educação é a econômica. Partimos do pressuposto que, para se ter educação de qualidade, são necessários recursos e investimentos substanciais a fim de garantir determinados insumos essenciais aos atos educativos. Não existe educação de qualidade sem a devida infraestrutura, sem profissionais dignamente remunerados e valorizados em suas carreiras, sem uma gestão que evite desperdícios, ou seja, que garanta eficiência econômica. Diversas pesquisas apontam que a gestão eficiente dos recursos econômicos melhora a qualidade. Podemos citar como exemplo dessa dimensão o Custo Aluno-Qualidade Inicial (CAQi), instrumento que busca a

[...] definição dos insumos mais importantes para os processos de ensinoaprendizagem (salários, jornada de trabalho, razão estudantes/professor, prédios e equipamentos, materiais de consumo e serviços) e em sua respectiva precificação, considerando as diferentes etapas de ensino. O CAQi consta nos documentos finais da Conferência Nacional de Educação Básica (Coneb), de 2008, e da Conferência Nacional de Educação (Conae), de 2010, e, após ampla discussão, foi aprovado por unanimidade pela Câmara de Educação Básica (CEB) do Conselho Nacional de Educação (CNE), em maio de 2010, na forma do Parecer CNE/CEB no 8/2010. Contudo, até o momento, esse parecer e a respectiva proposta de resolução não foram homologados pelo MEC, o que impede a sua entrada em vigor. (Pinto, 2015, p. 108).

Uma das ideias do CAQi é sistematizar prioridades de investimentos, ou seja, definir a eficiência do uso de recursos financeiros em educação de modo a garantir maior qualidade. Esse é apenas um exemplo de como a dimensão da eficiência 
econômica pode ser utilizada. Há, por outro lado, na visão de qualidade economicista, formas de se construir um "critério mercantil" dentro das escolas (Gentili, 2010, p. 126). Assim, partindo da ideia do custo-benefício, alguns impasses só podem ser resolvidos quando eliminados. Por exemplo, se a jornada em tempo integral tem um alto grau de investimento e o retorno não tem sido satisfatório, tal visão economicista encaminha sua supressão imediata, ao invés de buscar soluções e melhorias.

Nesse contexto, ancorado no ideário neoliberal, a dimensão econômica, comumente privilegiada em documentos de organismos financeiros (World Bank, 1995), ganha prioridade perante aspectos qualitativos de outras naturezas, inclusive os pedagógicos. Dessa forma, qualidade pode ganhar contornos de uma "retórica conservadora", em que poucos são privilegiados em detrimento da maioria, tendo como justificativa princípios de eficiência econômica.

\section{Dimensão da efetividade política}

Partimos da ideia de que educar deve sempre ser um "compromisso político" (Freire, 1967, p. 21), na medida em que não existe educação neutra, mas sempre carregada de sentidos, de valores, de crenças e de ideologias. A qualidade na/da educação, portanto, deve ser compreendida a partir de um compromisso político, com as devidas mediações. Não existe qualidade neutra, despida de significações. Como já afirmamos, qualidade não é um valor absoluto, mas uma instância relacional, que se articula com os diferentes contextos nos quais se insere.

Sander (2007, p. 98) afirma que a "dimensão política engloba as estratégias de ação organizada dos participantes do sistema educacional, suas escolas, universidades e outras organizações de educação e formação cidadã". Assim, pensar a efetividade política da qualidade é pensar a sua capacidade de mobilizar sujeitos e instituições. Diríamos, então, que não há qualidade sem uma visão político-cidadã de educação, sem um compromisso de transformação social.

Essa visão nos remete à clássica palestra de Theodor Adorno (1995), transmitida em 1965 e convertida em texto em 1967, que ilustra a necessidade de qualidade com compromisso social. Ao destacar a precisão e o ordenamento do nefasto campo de concentração nazista, o autor coloca em xeque a ideia de uma educação voltada para a eficiência, mas sem relação com o combate à barbárie. Para ter compromisso com a vida e a dignidade humana, a educação precisa emancipar e fomentar a consciência crítica (Adorno, 1995).

Assim, a qualidade na/da educação, para ser efetiva, não pode se furtar a estabelecer vínculos com a sua dimensão política, com os debates sobre cidadania, diversidade e injustiça. No cotidiano das escolas, isso se converte em temas como inclusão, combate ao bullying e ao preconceito, formação política e exercício democrático. Esses e outros são fatores qualitativos que marcam a educação, que a definem, e também são, de maneira dialética, definidos por ela.

O isolacionismo político, criticado por Sander (2007) ao analisar o caso da gestão, também é um problema para o debate da qualidade. A própria visão de 
gestão democrática e participativa é elemento-chave na busca incansável pela qualidade como uma utopia a ser efetivada. Por isso, a qualidade na/da educação requer o compromisso político apontado por Freire (1967) e se afasta das ideias de pseudoneutralidade, como hoje vemos em movimentos como o "Escola sem partido".

Assumir um papel político não significa partidarizar a educação, mas estabelecer um ambiente capaz de levar os sujeitos a desenvolverem seus pensamentos com liberdade e criticidade, a fazerem escolhas políticas conscientes e a se afastarem de qualquer forma de censura e alienação. Sem democracia, não há efetividade na qualidade na/da educação, pois faltará o contexto propício ao desenvolvimento cidadão dos sujeitos.

\section{Dimensão da relevância cultural}

Cultura e educação são indissociáveis. Pensar em qualidade na/da educação é pensar na diversidade cultural, no multiculturalismo e na interculturalidade como caminhos para sua efetivação. A relevância cultural da educação precisa ser priorizada, na medida em que a escola é espaço do encontro das culturas, mas também de choques, opressões e invisibilizações.

A relevância cultural da qualidade cumpre um duplo papel (estético e ético), tendo, como diria Freire (1996, p. 32), "decência e boniteza de mãos dadas". A qualidade passa por valores estéticos, pelo cuidado com o ambiente, com as pessoas, com a arte e com a cultura, mas também pelo valor moral: de nada adianta uma bela figura sem o devido conteúdo. A ética é inerente à estética e a cultura precisa pensar novas formas estéticas, formas multiculturais, que rompam com as versões hegemônicas de feio e belo, certo e errado, popular e erudito.

A distinção entre alta e baixa cultura, consolidando a ideia de uma suposta "boa vontade cultural" apontada por Bourdieu (2013), contribui para desqualificar o debate da relevância cultural. A qualidade na/da educação precisa passar pela multiplicidade de produtores culturais, uma cultura que combata o racismo, o sexismo, a xenofobia e quaisquer outras fobias sociais que oprimam minorias.

Nas palavras de Candau (2011, p. 253),

A dimensão cultural é intrínseca aos processos pedagógicos, "está no chão da escola" e potencia processos de aprendizagem mais significativos e produtivos, na medida em que reconhece e valoriza a cada um dos sujeitos neles implicados, combate todas as formas de silenciamento, invisibilização e/ou inferiorização de determinados sujeitos socioculturais, favorecendo a construção de identidades culturais abertas e de sujeitos de direito, assim como a valorização do outro, do diferente, e o diálogo intercultural. Esta tem sido uma busca que tem orientado muitas de minhas atividades nos últimos anos e também de inúmeros educadores e educadores (sic) que, desde o "chão da escola", se atrevem a reconhecer e valorizar as diferenças presentes no seu dia a dia.

Assim, dentro do paradigma multidimensional, não se pode ter qualidade sem que as múltiplas culturas dos diferentes sujeitos sejam valorizadas e respeitadas, seja no chão da escola, seja nas políticas públicas educacionais. Qualidade na/da educação requer um olhar plural para as culturas que se desenham na sociedade, 
propiciando acolhimento e transformação. Sander (2007, p. 99) completa dizendo que a relevância cultural garante uma educação baseada em valores éticos e comprometidos com a "qualidade de vida e o desenvolvimento humano".

\section{Considerações finais}

Como vimos, há diversas formas de se compreender qualidade na/da educação. Fatores sociais, políticos, históricos, geográficos, econômicos, culturais e educacionais interferem nos julgamentos realizados e na distinção que se faz entre escolas de boa ou de má qualidade, bons e maus alunos, professores competentes ou incompetentes, políticas públicas eficazes ou ineficazes, gestores eficientes ou ineficientes.

A história nos mostra que tais conceituações se modificam a partir de imperativos sociais. No Brasil, por exemplo, Oliveira e Araújo (2005, p. 8) nos apontam que qualidade foi entendida pelo senso comum a partir de três formas distintas:

De um ponto de vista histórico, na educação brasileira, três significados distintos de qualidade foram construídos e circularam simbólica e concretamente na sociedade: um primeiro, condicionado pela oferta limitada de oportunidades de escolarização; um segundo, relacionado à ideia de fluxo, definido como número de alunos que progridem ou não dentro de determinado sistema de ensino; e, finalmente, a ideia de qualidade associada à aferição de desempenho mediante testes em larga escala.

Inicialmente, qualidade estava atrelada à exclusividade das elites em acessar o ensino. Ou seja, o acesso controlado à educação era o que garantiria seu bom desempenho. Quando houve o alargamento de direitos e as camadas populares começaram a ter acesso à educação, sobretudo a partir dos anos 1930, escola de qualidade passou a ser aquela que é "forte" nos estudos, na qual o aluno tem dificuldades para tirar boas notas e passar de ano. Nos anos 1990, qualidade assume um novo significado, mensurado a partir de rankings e da política performática das avaliações de larga escala.

Isso mostra que a visão mais geral sobre qualidade na/da educação no Brasil sempre foi unidimensional, privilegiando ora aspectos políticos e econômicos, ora aspectos educacionais e culturais. Nunca houve uma compreensão multidimensional, na qual os quatro aspectos fossem atendidos para que a qualidade se efetivasse.

Pensar qualidade somente a partir de uma lógica economicista, com investimentos e resultados, nos parece uma simplificação que desconsidera os aspectos pedagógicos e culturais inerentes à formação humana. Entretanto, deixar de lado a necessidade de eficiência econômica e efetividade política pode nos fazer cair em abstrações vazias, na ideia de uma educação que existe somente em teoria, pois na prática não é factível. Por isso, pensar em qualidade na/da educação é, em última instância, pensar em diferentes qualidades. O que propomos aqui é uma nova epistemologia das qualidades na/da educação, por meio do paradigma multidimensional. Concordamos com Esteban (2008, p. 7), quando afirma que: 
A ideia de qualidade unívoca e no singular se insere em um projeto de escola comprometido com a busca de um enquadramento que homogeneíza culturas, valores, conhecimentos e práticas, em um contexto social profundamente marcado pelo predomínio da epistemologia positivista.

Romper com a visão positivista, que simplifica o pensamento, e adentrar uma visão complexa, plural e multidimensional nos possibilita discutir qualidade(s) a partir de outro patamar investigativo, não só a partir de um ou outro aspecto, mas com/no emaranhado de conexões que congrega percepções distintas, mas igualmente válidas. Uma ideia que se assemelha ao que Bondioli (2004) chama de "qualidade negociada", uma construção coletiva, reflexiva, processual e polifônica. Trata-se, portanto, de um exercício teórico-epistemológico libertador e inovador, que pode lançar luz sobre questões antes obscuras.

\section{Referências bibliográficas}

ADAMS, D. Defining educational quality. Arlington: Institute for International Research, 1993.

ADORNO, T. W. Educação após Auschwitz. In: ADORNO, T. W. Educação e emancipação. Rio de Janeiro: Paz \& Terra, 1995. p. 119-138. Disponível em: $<$ https://rizomas.net/arquivos/Adorno-Educacao-apos-Auschwitz.pdf > . Acesso em: 18 nov. 2020.

AZEVEDO, F. et al. A reconstrução educacional no Brasil ao povo e ao governo: manifesto dos pioneiros da educação nova. São Paulo: Companhia Editora Nacional, 1932. Edição publicada em 2010 pela Fundação Joaquim Nabuco está disponível em: <http://www.dominiopublico.gov.br/download/texto/me4707.pdf>. Acesso em 18 nov. 2020.

AZEVEDO, J. M. L. Notas sobre a análise da gestão da educação e da qualidade do ensino no contexto das políticas educativas. Revista Brasileira de Política e Administração da Educação, Brasília, v. 27, n. 3, p. 409-432, set./dez. 2011.

BANCO MUNDIAL. A educação na África Subsaariana: medidas de política para ajustamento, revitalização e expansão. Washington, DC, [1988] 1990. (Estudo de Política Geral do Banco Mundial). Disponível em: < http://documents1.worldbank. org/curated/en/564661468007859315/pdf/97770PUBOPORTUGESEOBox34494B0 1PUBLIC1.pdf>. Acesso em: 18 nov. 2020.

BANCO MUNDIAL ver também World Bank.

BEEBY, C. E. The quality of education in developing countries. Cambridge, USA: Harvard University Press, 1966.

BONDIOLI, A. (Org.). O projeto pedagógico da creche e sua avaliação: a qualidade negociada. Campinas: Autores Associados, 2004 
BOURDIEU, P. A distinção: crítica social do julgamento. Porto Alegre: Zouk, 2013.

BRASIL. Constituição (1988). Constituição da República Federativa do Brasil. Brasília: Câmara dos Deputados, 1988. Disponível em: < http://www.planalto.gov. br/ccivil_03/constituicao/constituicaocompilado.htm>. Acesso em: 18 nov. 2020.

BRASIL. Lei no 9.394, de 20 de dezembro de 1996. Estabelece as diretrizes e bases da educação nacional. Diário Oficial da União, Brasília, DF, 23 dez. 1996. Seção 1, p. 27833. Disponível em: < http://www.planalto.gov.br/ccivil_03/leis/ 19394.htm>. Acesso em: 18 nov. 2020.

CANDAU, V. M. F. Diferenças culturais, cotidiano escolar e práticas pedagógicas. Currículo sem Fronteiras, [S. 1.], v.11, n.2, p. 240-255, jul./dez. 2011. Disponível em: <https://saopauloopencentre.com.br/wp-content/uploads/2019/05/candau. pdf>. Acesso em: 18 nov. 2020.

COLEMAN, J. S. et al. Equality of educational opportunity. Washington, DC: Government Printing Office, 1966.

CURY, C. R. J. Qualidade em educação. Nuances: Estudos sobre Educação, São Paulo, v. 17, n. 18, p. 15-31, jan./dez. 2010.

DECLARAÇÃO Mundial sobre Educação para Todos e plano de ação para satisfazer as necessidades básicas de aprendizagem. Jomtien, Tailândia, 1990. Disponível em: <https://unesdoc.unesco.org/ark:/48223/pf0000086291_por>. Acesso em: 28 set. 2020 .

DEMO, P. Educação e qualidade. Campinas: Papirus, 2009. (Coleção Magistério: Formação e Trabalho Pedagógico).

DEWEY, J. Democracia e educação. São Paulo: Companhia Editora Nacional, [1916] 1936.

DOURADO, L. F.; OLIVEIRA, J. F.; SANTOS, C. A. A qualidade da educação: conceitos e definições. Brasília: Inep, 2007. (Série Documental. Textos para Discussão, 24). 33 p. Disponível em: < http://portal.inep.gov.br/ documents/186968/485287/A + qualidade+da + educa\%C3\%A7\%C3\%A3o+concei tos+e+defini\%C3\%A7\%C3\%B5es/>. Acesso em 18 nov. 2020.

ESTEBAN, M. T. Silenciar a polissemia e invisibilizar os sujeitos: indagações aos discursos sobre a qualidade da educação. Revista Portuguesa de Educação, Braga, v. 21, n. 1, p. 5-31, 2008.

FERREIRA, A. B. H. Novo Aurélio Século XXI: o dicionário da língua portuguesa. Rio de Janeiro: Nova Fronteira, 1999.

FREIRE, P. Educação como prática da liberdade. Rio de Janeiro: Paz \& Terra, 1967.

FREIRE, P. Pedagogia da autonomia: saberes necessários à prática educativa. Rio de Janeiro: Paz \& Terra, 1996. 
GADOTTI, M. Qualidade na educação: uma nova abordagem. São Paulo: Editora e Livraria Instituto Paulo Freire, 2010. (Cadernos de formação, 5).

GATTI, B. A. A construção da pesquisa em educação no Brasil. Brasília: Liber Livro, 2010. (Série Pesquisa, 1).

GENTILI, P. O discurso da "qualidade" como nova retórica conservadora no campo educacional. In: GENTILI, P.; SILVA, T. T. (Orgs.). Neoliberalismo, qualidade total e educação: visões críticas. Petrópolis: Vozes, 2010. p. 111-177.

JENCKS, C. Inequality: a reassessment of the effects of family and schooling in America. New York: Basic Books, 1972.

KUHN, T. S. A estrutura das revoluções científicas. São Paulo: Perspectiva, 1982.

MADAUS, G. F.; AIRASIAN, P.W.; KELLAGHAN, T. School effectiveness: a reassessment of the evidence. New York: McGraw-Hill Book Company, 1980.

MAGER, R. F.; PIPE, P. Análise de problemas de desempenho ou "você precisa realmente querer". Porto Alegre: Globo, [1970] 1976.

MORIN, E. Introdução ao pensamento complexo. Porto Alegre: Sulina, 2007.

OLIVEIRA, R. P.; ARAÚJO, G. C. Qualidade do ensino: uma nova dimensão da luta pelo direito à educação. Revista Brasileira de Educação, Rio de Janeiro, n. 28, p. 5-23, jan./abr. 2005.

PINTO, J. M. R. O Fundeb na perspectiva do custo aluno qualidade. Em Aberto, Brasília, v. 28, n. 93, p. 101-117, jan./jun. 2015.

SAMMONS, P. As características-chave das escolas eficazes. In: BROOKE, N.; SOARES, J. F. (Orgs.). Pesquisa em eficácia escolar: origens e trajetórias. Belo Horizonte: Editora UFMG, 2008. p. 335-392.

SANDER, B. Administração da educação no Brasil: genealogia do conhecimento. Brasília: Liber Livro, 2007.

SANTANA, F. F. A dinâmica da aplicação do termo qualidade na educação superior brasileira. São Paulo: Editora SENAC, 2007.

SILVA, V. G. A narrativa instrumental da qualidade na educação. Estudos em Avaliação Educacional, São Paulo, v. 19, n. 40, p. 191-221, maio/ago. 2008.

SOUZA, S. Z. L.; OLIVEIRA, R. P. Políticas de avaliação da educação e quase mercado no Brasil. Educação \& Sociedade, Campinas, v. 24, n. 84, p. 873-895, set. 2003

TEIXEIRA, A. Educação não é privilégio. São Paulo: Companhia Editora Nacional, 1957. 
TORRES, R. M. Melhorar a qualidade da educação básica? As estratégias do Banco Mundial. In: DE TOMMASI, L.; WARDE, M.; HADDAD, S. (Orgs.). O Banco Mundial e as políticas educacionais. São Paulo: Cortez, 2000. p. 125-194.

UNESCO. Educação para todos: o imperativo da qualidade. São Paulo: Moderna, 2005. Disponível em: < https://unesdoc.unesco.org/ark:/48223/pf0000139079>. Acesso em: 28 set. 2020.

UNICEF. Defining quality in education [Definindo qualidade em educação]. New York, 2000. Available in: <https://www.right-to-education.org/sites/ right-to-education.org/files/resource-attachments/UNICEF_Defining_Quality_ Education_2000.PDF> Access in: 28 Sept. 2020.

WORLD BANK. Priorities and strategies for education: a World Bank review [Prioridades e estratégias para a educação: um estudo do Banco Mundial]. Washington, DC: World Bank, 1995. (Development in practice). Disponível em: < http://documents1.worldbank.org/curated/pt/117381468331890337/pdf/multipage.pdf $>$. Acesso em: 18 nov. 2020.

WORLD BANK ver também Banco Mundial.

Marcelo Mocarzel, doutor em Comunicação pela Pontifícia Universidade Católica do Rio de Janeiro (PUC-Rio), com pós-doutorado em Educação na Universidade Federal Fluminense (UFF), é professor do Programa de Pós-Graduação em Educação da Universidade Católica de Petrópolis (UCP) e dos cursos de graduação e pós-graduação do Centro Universitário La Salle do Rio de Janeiro (Unilasalle-RJ). É membro do Conselho Estadual de Educação do Rio de Janeiro, além de gestor escolar há mais de dez anos. É pesquisador do Núcleo de Estudos e Pesquisas em Gestão e Políticas Públicas em Educação (Nugeppe/UFF).

marcelomocarzel@gmail.com

Jorge Najjar (in memoriam), doutor em Educação pela Universidade de São Paulo (USP), foi professor titular da Faculdade de Educação da Universidade Federal Fluminense (UFF), chefe de departamento, vice-diretor e diretor da faculdade e coordenador do Programa de Pós-Graduação. Também atuou como membro do Conselho Estadual de Educação do Rio de Janeiro. Fundador e líder do Núcleo de Estudos e Pesquisas em Gestão e Políticas Públicas em Educação (Nugeppe/UFF). Faleceu em 19 de agosto de 2020.

Recebido em 16 de junho de 2020

Aprovado em 8 de setembro de 2020 